\title{
IDENTIFIKASI PERAN PERCEIVED ORGANIZATIONAL SUPPORT TERHADAP KESEIMBANGAN HIDUP-KERJA
}

\author{
Oleh : Yuki Fitria, SE., MM, yuki.fifit@gmail.com \\ FAKULTAS EKONOMI - UNIVERSITAS NEGERI PADANG
}

\begin{abstract}
The aim of this study is to identify the influence of perceived organizational support on work-life balance of women employees in banking sector in Padang city. Sample is chosen by using purposive technique with some criteria namely married woman employees and have been employed for 5 or more years. The number of sample was 97 . The data used are the primary data that collected through a questionnaire. The resulting data will be analyzed using regression analysis by SPSS.

The research shows that, Perceived Organizational Support (POS) has positive and significant influence on female employees work-life balance in banking sector in Padang City.
\end{abstract}

Keyword: perceived organizational support and work-life balance

\section{PENDAHULUAN}

Beberapa tahun terakhir terjadi perubahan pada jadwal kerja karyawan di organisasi. Banyak karyawan harus bekerja pada hari sabtu dan minggu. Terdapat perbedaan pola pada waktu kerja, yang berbeda dari standar, yaitu dari jam 8 pagi sampai jam 5 sore (Bharat, 2009). Meningkatnya beban kerja mengharuskan karyawan untuk menunjukkan komitmennya terhadap organisasi dalam cara yang lebih nyata (Ishaya dan Ayman, 2008). Konsekuensinya, semakin banyak waktu yang mereka habiskan di tempat kerja, akan mengurangi waktunya di rumah.

Perkembangan teknologi dan internet memungkinkan organisasi untuk tetap berhubungan dengan karyawannya ketika siang dan malam (Morgan, 2003). Hal ini menyebabkan tuntutan kerja yang lebih berat pada karyawan. Ini mengakibatkan meningkatnya laporan stress dan ketidak seimbangan kerja (Bhagwagar, 2009). Hal ini menyebabkan hilangnya pemisah antara kehidupan kerja dengan kehidupan keluarga.

Isu keseimbangan hidup-kerja (work life balance) dominan muncul saat jumlah wanita yang memasuki pasar tenaga kerja semakin banyak dan menghasilkan peran 
ganda; ibu dalam keluarga yang sekaligus bekerja sebagai pencari nafkah keluarga. Pada dasarnya wanita pergi keluar untuk bekerja, hampir tidak ada perubahan pola pada tanggung jawab wanita di rumah tangga (Singh, 2004). Wanita tetap bertanggung jawab pada pekerjaan rumah tangga dan mengasuh anak.

Perubahan dalam pekerjaan dan kehidupan keluarga mengharuskan karyawan untuk terus-menerus mengupayakan agar terjadi keseimbangan antara kehidupan keluarga dan kerja. Penelitian Jenkins (2000) mengamati bahwa dalam urusan mengasuh anak, keharusan untuk menyeimbangkan berbagai peran berdampak terhadap kesehatan dan hubungan keluarga. Summer dan Knight (2001) mengemukakan bahwa terdapat perbedaan gender dalam menghadapi masalah pekerjaan dan keluarga. Wanita masih harus mengemban tanggung jawab utama dalam pekerjaan rumah tangga, terlepas dari status pekerjaannya. Jadi, banyak karyawan wanita yang terus menghadapi kesulitan untuk menyeimbangkan keduanya (Hyman dan Summer, 2004). Pekerjaan yang mendukung wanita secara positif berhubungan dengan kepuasan kerja, komitmen organisasional, dan pencapaian karir (Marcinkus, Whelan-Beny, dan Gordon, 2007).

Setiap karyawan lebih menyukai bekerja di organisasi yang mendukung keseimbangan hidup-kerja. Namun karyawan pria lebih beruntung dibandingkan karyawan wanita. Menurut Burke (2002), pria akan merasa lebih puas apabila mereka meraih prestasi lebih banyak dalam pekerjaan, walaupun dengan harga harus menelantarkan keluarga. Di lain pihak, stress yang dialami wanita di tempat kerja dan di lingkungan keluarga sama pentingnya, dan keduanya merupakan sumber kepuasan bagi wanita. Akan tetapi, keluarga tetap menjadi prioritas. Ketika pekerjaan tidak mengizinkan wanita untuk mengurus keluarga, mereka merasa tidak bahagia, kecewa, dan frustasi. Mereka menetapkan garis pemisah yang tegas antara pekerjaan dan keluarga dan mereka tidak suka ketika keduanya saling bersilangan (Burke, 2002). Seperti halnya karyawan wanita di industri perbankan. Perbankan termasuk perusahaan yang high technology and high service, sehingga tuntutan akan pekerjaan sangat tinggi, dimana karyawan wanita sangat terikat dengan jam kerja yang berlaku tanpa ada perbedaan dengan karyawan pria. Hal inilah yang menyebabkan stress kerja pada karyawan wanita menjadi tinggi, terutama bagi mereka yang telah berkeluarga dan memiliki anak. 
Dengan demikian masalah keseimbangan hidup-kerja perlu menjadi perhatian perusahaan. Kemampuan untuk menjaga keseimbangan antara kehidupan kerja, kehidupan keluarga, dan sosial menjadi sangat penting. Keseimbangan hidup-kerja akan membuat karyawan menjadi lebih termotivasi, produktif, dan mengurangi stress. The Work Foundation mendefinisikan keseimbangan hidup-kerja sebagai individu yang mempunyai kontrol terhadap kapan, dimana, dan bagaimana mereka bekerja, yang mengarah pada kemampuan untuk menikmati kualitas hidup yang optimal. Sementara itu, Hill, Hawkins, Ferris, dan Weintzman (2001) mendefinisikan keseimbangan hidup-kerja sebagai kemampuan individu untuk menyeimbangkan komitmen terhadap keluarga dan pekerjaan, serta tanggung jawab dan aktivitas di luar pekerjaan lainnya. Keseimbangan hidup dan kerja tercapai ketika hak untuk hidup seutuhnya di dalam dan di luar pekerjaan diterima dan dijunjung tinggi sebagai norma yang saling menguntungkan bagi bisnis, individu dan masyarakat.

Untuk dapat meningkatkan peran kesimbangan hidup-kerja bagi karyawan, maka sangat penting bagi perusahaan untuk mengetahui faktor-faktor apa saja yang menyebabkan timbulnya atau meningkatnya kesimbangan hidup-kerja bagi karyawan. Banyak variabel yang bisa mempengaruhi terciptanya keseimbangan hidup-kerja individu, yang berasal dari faktor pekerjaan, keluarga, dan lingkungan sosial, diantaranya dukungan organisasional yang dirasakan (Perceived Organizational Support / POS) (Thakur dan Kumar, 2015). POS mengacu kepada kepercayaan karyawan secara keseluruhan terkait sejauh mana perusahaan menghargai karyawan, peduli terhadap kesejahteraanya, dan mendukung kebutuhan sosial-emosional karyawan dengan menyediakan sumber daya untuk membantu (Eisenberger, Huntington, Hutchison, dan Sowa, 1986). Dukungan dari organisasi dalam menciptakan keseimbangan hidup-kerja bagi karyawannya diharapkan dapat membantu karyawan dalam mencapai keseimbangan hidup-kerja tersebut.

Dukungan dari organisasi yang dirasakan dalam penelitian ini diharapkan dapat memberikan pengaruh positif terhadap keseimbangan hidup-kerja. Dengan meningkatnya kualitas kehidupan, maka rumah tangga dengan kedua orang tua bekerja di luar rumah, semakin meningkat. Hal yang perlu menjadi perhatian adalah, ketika wanita yang bekerja juga berperan dominan dalam kehidupan rumah tangga. Walaupun pria menunjukkan 
minat yang meningkat untuk menyeimbangkan komitmen kerja dengan perannya dalam keluarga, tetap wanitalah yang mengalami level konflik yang lebih tinggi, karena mereka diharapkan dapat mengerjakan pekerjaan rumah tangga, mengurus keluarga dan menyelesaikan pekerjaan dengan baik (Burke, 2001).

Penelitian ini memfokuskan keseimbangan hidup-kerja pada karyawan wanita, khususnya karyawan wanita dalam perusahaan perbankan dikarenakan level konflik yang lebih tinggi antara keseimbangan hidup-kerja terjadi pada karyawan wanita (Burke, 2001). Oleh karena itu, peneliti membuat penelitian yang berjudul "Identifikasi Peran Perceived Organizational Support terhadap Keseimbangan Hidup-Kerja”.

Sesuai dengan latar belakang masalah yang telah diuraikan di atas, maka yang menjadi pertanyaan dalam penelitian ini adalah sejauhmana pengaruh Perceived Organizational Support (POS) terhadap Keseimbangan Hidup-Kerja pada karyawan wanita dalam perusahaan perbankan di Kota Padang.

\section{TINJAUAN PUSTAKA}

\section{A. Keseimbangan hidup-kerja}

Beberapa tahun terakhir isu keseimbangan hidup-kerja semakin banyak diteliti (Noor, 2011). Setiap individu pada dasarnya perlu untuk mengekspresikan dan memenuhi kebutuhan mereka untuk kesenangan dan rekreasi. Diluar pekerjaan formal mereka yang dibayar, para karyawan juga mempunyai pekerjaan yang tidak dibayar, seperti merawat anak, tanggung jawab terhadap pasangan, memasak, membersihkan, dan waktu luang untuk bersantai (Collins 2007 dalam Shankar dan Bhatnagar, 2010). Sehingga saat ini isu keseimbangan hidup-kerja (work life balance) menjadi relevan bagi semua individu (Guest, 2002).

Keseimbangan hidup-kerja mempunyai pengaruh yang penting pada sikap karyawan terhadap organisasi dan juga terhadap kehidupan karyawan (Scholaris dan Marks, 2004:54). Terdapat kemungkinan untuk meneliti kecenderungan dari keseimbangan hidup-kerja dan perkembangannya yang mempengaruhi kesejahteraan karyawan dan hasil pekerjaannya (Guest, 2002). Mendefinisikan keseimbangan hidupkerja merupakan hal yang sulit, mengingat di dalamnya terdapat beberapa dimensi. The Work Foundation mendefinisikan keseimbangan kehidupan - kerja sebagai individu yang 
mempunyai kontrol terhadap kapan, dimana, dan bagaimana mereka bekerja, yang mengarah pada kemampuan untuk menikmati kualitas hidup yang optimal. Sementara itu, Hill et al., (2001) mendefinisikan keseimbangan hidup - kerja sebagai kemampuan individu untuk menyeimbangkan komitmen terhadap keluarga dan pekerjaan, serta tanggung jawab dan aktivitas di luar pekerjaan lainnya. Keseimbangan hidup dan kerja tercapai ketika hak untuk hidup seutuhnya di dalam dan di luar pekerjaan diterima dan dijunjung tinggi sebagai norma yang saling menguntungkan bagi bisnis, individu dan masyarakat.

Menyeimbangkan kesuksesan karir dengan kehidupan pribadi atau keluarga dipercaya dapat bermanfaat bagi kepuasan kerja individu (Broers, 2005). Bagi perusahaan, keseimbangan hidup-kerja dapat bermanfaat dikarenakan dapat membuat karyawan menjadi lebih termotivasi, produktif dan stress kerja menjadi berkurang. Hal ini akan mengarah pada: (1) membuat karyawan merasa lebih dihargai, (2) menarik kandidat dengan range yang lebih luas, (3) meningkatkan produktivitas, (4) mengurangi absensi, (5) reputasi menjadi perusahaan yang terpilih, (6) mempertahankan karyawan yang bernilai, (7) mengurangi biaya, dan (8) memaksimalkan tenaga kerja yang ada.

Bagi karyawan terdapat keuntungan menjadi lebih bahagia dengan pekerjaan dan di rumah, diantaranya: (1) memiliki tanggung jawab yang lebih besar dan rasa memiliki terhadap organisasi, (2) memiliki hubungan yang lebih baik dengan manajemen, (3) meningkatnya harga diri, rasa percaya diri, kesehatan, konsentrasi dan percaya diri, (4) memperlihatkan loyalitas dan komitmen, (4) tidak membawa masalah dari rumah ke tempat kerja, dan sebaliknya, (5) memiliki waktu untuk lebih focus pada kehidupan di luar pekerjaan, dan (6) memiliki kendali lebih besar dalam mengontrol kehidupan pekerjaan.

Keseimbangan hidup-kerja di tempat kerja dapat dilihat dari beberapa indikator, yaitu: (1) waktu yang fleksibel, (2) waktu libur, (3) waktu kerja yang lebih singkat, (4) berbagi pekerjaan, (5) bekerja dari rumah, (6) teleworking, (7) waktu rehat dari pekerjaan, dan (8) keuntungan yang fleksibel. 


\section{B. Perceived Organizational Support (POS)}

POS adalah tingkat dimana karyawan yakin bahwa organisasi menghargai kontribusi mereka dan peduli dengan kesejahteraan mereka (Robbins dan Judge, 2009). Karyawan pada umumnya memperhatikan komitmen organisasi terhadap mereka. Adapun bentuk penghargaan organisasi bagi karyawan, seperti dalam persetujuan, rasa hormat, gaji dan promosi, dan akses terhadap informasi (Rhoades dan Eisenberger, 2002). Jika karyawan merasakan komitmen dari organisasi, terdapat kecendrungan dari mereka untuk menunjukan perilaku balasan, berupa peningkatan komitmen terhadap organisasi. Dimana karyawan yang secara emosional berkomitmen terhadap organisasi menunjukkan kinerja yang bagus, absensi yang berkurang, dan berkurangnya niat untuk meninggalkan perusahaan (Mathiew dan Zajac, 1990). POS menimbulkan rasa berhutang dalam diri karyawan dan itu hanya dapat dikurangi dengan memberikan umpan balik. POS yang tinggi diperkirakan akan menghasilkan balasan berupa sikap dan perilaku positif yang menguntungkan organisasi.

Teori dukungan organisasi (Eisenberger, Huntington, Hutchison, dan Sowa, 1986) mengemukakan bahwa untuk mengukur kesiapan organisasi untuk menghargai usaha kerja yang berlebih dan untuk mencapai kebutuhan sosioemosional, karyawan membangun kepercayaan umum terkait sejauh mana organisasi menghargai kontribusi mereka dan peduli terhadap kesejahteraannya. Perceived organizational support (POS) adalah persepsi karyawan terhadap sejauh mana organisasi menghargai mereka dan peduli terhadap mereka.

Dalam penelitian ini, POS diharapkan dapat membantu karyawan dalam menciptakan keseimbangan hidup kerja. Rhoades dan Eisenberger (2002) merekomendasikan 8 item untuk mengukur tingkat Perceived Organizational Support, yaitu:

1. Organisasi menghargai kontribusi karyawan

Sejauh mana organisasi menghargai pekerjaan dan peran dari karyawan dalam sebuah pekerjaan. Salah satu contoh kontribusi penting karyawan adalah dalam bentuk penyampaian ide. Setelah karyawan memberikan ide tersebut bagaimana organisasi menanggapi dan menindaklanjuti ide tersebut.

2. Organisasi menghargai usaha ekstra yang telah karyawan berikan. 
Tidak jarang karyawan dalam sebuah organisasi memberikan usaha lebih dari yang diwajibkan, dari hal tersebut organisasi akan memberikan ekstra juga kepada karyawan tersebut, seperti terpilih menjadi employee of the week, kenaikan pangkat, kenaikan gaji.

3. Organisasi memperhatikan segala keluhan karyawan.

Seberapa dalam organisasi memperhatikan karyawan, mendengarkan apa yang telah karyawan alami dan menerima masukan dari para karyawan.

4. Organisasi sangat peduli tentang kesejahteraan karyawan.

Peduli tentang kesejahteraan karyawan dapat dilakukan oleh organisasi, seperti memberikan peralatan yang memadai untuk kelangsungan kerja para karyawan, memberikan asuransi kepada karyawan yang bekerja.

5. Organisasi akan membantu karyawan apabila tidak melakukan pekerjaan dengan baik.

Sebuah kesalahan dalam pekerjaan adalah hal yang wajar dan akan sering ditemui pada pribadi masing-masing karyawan, akan tetapi pihak organiasi harus tetap memantau kinerja para karyawan, jika memang tidak sesuai standar yang sudah diberikan kepadanya maka pihak organisasi harus menegur karyawan tersebut aga dapat memperbaiki kinerja para karyawan.

6. Organisasi peduli dengan kepuasan secara umum terhadap pekerjaan karyawan.

Organisasi memperhatikan dan mengevaluasi sampai mana karyawannya merasa puas akan pekerjaan yang diberikan organisasi kepada karyawannya.

7. Organisasi menunjukkan perhatian yang besar terhadap karyawan.

Banyak organisasi yang memberikan support kepada para karyawan yang bekerja padanya salah satu support yang dapat diberikan adalah perhatian yang besar terhadap karyawan, seperti kesehatan keluarga karyawan.

8. Organisasi merasa bangga atas keberhasilan karyawan dalam bekerja.

Kemajuan sebuah organisasi akan muncul dari sebuah pencapaian yang dihasilkan para karyawan. Tentunya pihak organisasi memiliki rasa bangga memiliki para karyawan yang bekerja di dalam organisasi tersebut. 


\section{Kerangka Konseptual}

Perubahan dalam pekerjaan dan kehidupan keluarga mengharuskan karyawan untuk terus-menerus mengupayakan tindakan untuk menyeimbangkannya. Keseimbangan hidup-kerja mempunyai pengaruh yang penting pada sikap karyawan terhadap organisasi dan juga terhadap kehidupan karyawan. Baik pria dan wanita lebih menyukai bekerja di organisasi yang mendukung keseimbangan hidup-kerja. Pria lebih beruntung dibandingkan wanita. Pria akan merasa lebih puas apabila mereka meraih prestasi lebih banyak dalam pekerjaan, walaupun dengan harga harus menelantarkan keluarga. Di lain pihak, stress yang dialami wanita di tempat kerja dan di lingkungan keluarga sama pentingnya, dan keduanya merupakan sumber kepuasan bagi wanita.

Banyak variabel yang bisa mempengaruhi terciptanya keseimbangan hidup-kerja individu, diantaranya dukungan organisasional yang dirasakan (Perceived Organizational Support / POS). POS mengacu kepada kepercayaan karyawan secara keseluruhan terkait sejauh mana perusahaan menghargai karyawan, peduli terhadap kesejahteraanya, dan mendukung kebutuhan sosial - emosional karyawan dengan menyediakan sumber daya untuk membantu. Dukungan dari organisasi dalam menciptakan keseimbangan hidupkerja bagi karyawannya, diharapkan dapat membantu karyawan dalam mencapai keseimbangan hidup - kerja tersebut.

Berikut adalah kerangka konseptual dari penelitian ini :

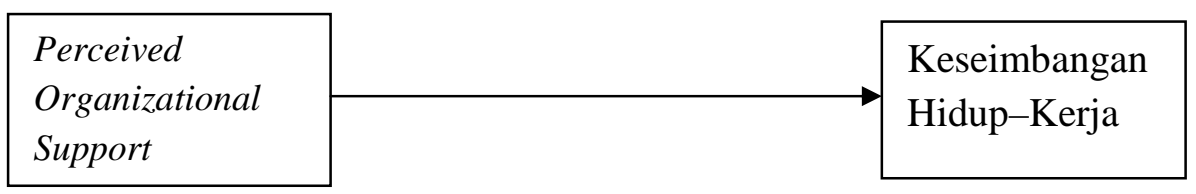

Gambar 1 : Kerangka Konseptual

Adapun hipotesis dari penelitian ini adalah :

H1: Perceived Organizational Support (POS) berpengaruh positif dan signifikan terhadap Keseimbangan Hidup - Kerja 


\section{METODE PENELITIAN}

Desain penelitian yang digunakan adalah studi konfirmatori (confirmatory study). Desain penelitian meliputi tujuan, unit analisis, dan jenis data. Tujuan penelitian ini adalah pengujian hipotesis dengan menggunakan metode survei. Keseimbangan hidupkerja merupakan fenomena sosial yang akan ditangkap dan bisa digeneralisasi dengan lebih baik jika menggunakan metode survei (Kerlinger \& Lee, 2000). Unit analisis pada penelitian ini adalah individu.

\section{Populasi dan Sampel}

Menurut Cooper dan Schindler (2011) populasi merupakan kumpulan dari keseluruhan elemen atau objek yang akan diteliti. Objek dalam penelitian ini adalah karyawan wanita yang bekerja di industri perbankan di Kota Padang, Sumatera Barat. Untuk populasi yang tidak diketahui dan tidak memiliki sample frame, Cooper dan Schindler (2011) mengatakan bahwa teknik pengambilan sampel yang dapat digunakan adalah non-probability sampling.

Pada penelitian ini teknik pengambilan sampel yang akan dipakai adalah teknik purposive, dengan kriteria yang ditetapkan yaitu karyawan wanita di perbankan yang telah berkeluarga, dengan masa kerja lebih dari 5 tahun. Jumlah responden untuk penelitian survei minimal 30 orang (Hair, Black, Babin, dan Anderson, 2010). Penelitian ini merupakan penelitian survei yang salah satu keunggulannya terletak pada generalisasi, maka semakin banyak responden yang digunakan akan semakin baik (Kerlinger \& Lee, 2000).

Kuisioner disebarkan sebanyak 120 unit, namun yang dikembalikan hanya 110 unit. Setelah diperiksa dan disesuaikan dengan kriteria sampel, maka kuisioner yang layak dipakai hanya sebanyak 97 unit. Jadi yang menjadi sampel dalam penelitian ini adalah sebanyak 97 orang.

\section{Sumber dan Jenis Data}

Dalam penelitian ini peneliti menggunakan sumber data primer. Data primer yaitu data yang diperoleh langsung dari responden penelitian di lapangan. Data primer yang dipakai adalah kuesioner yang digunakan untuk mengukur keseimbangan hidup - kerja, perceived organizational support. 


\section{Metode Pengumpulan Data}

Penelitian ini merupakan penelitian kuantitatif dengan menggunakan metode survei. Data dari penelitian ini diperoleh melalui penyebaran kuesioner. Kuesioner terdiri atas dua bagian; (1) berisi pertanyaan mengenai karakteristik demografi responden, termasuk latar belakang pendidikan dan latar belakang fungsional, (2) berisi pernyataan tentang variabel keseimbangan hidup-kerja dan perceived organizational support. Kuesioner bagian pertama untuk latar belakang pendidikan dan latar belakang fungsional, masing-masing bersifat kategorikal. Kuesioner bagian kedua, berupa pernyataan dengan skala semantik differensial, dalam bentuk bukan pilihan ganda maupun checklist, tetapi tersusun dalam satu garis kontinum dimana jawaban yang sangat positif terletak di bagian kanan garis dan jawaban yang sangat negatif terletak dibagian kiri garis, atau sebaliknya. Kuesioner dalam penelitian ini akan diberikan secara pribadi (self-administrated survey).

\section{HASIL PENELITIAN}

Sebelum dilakukan uji hipotesis, dilakukan uji normalitas data untuk mengetahui apakah sebaran data terdistribusi normal atau tidak. Uji asumsi yang dilakukan dalam penelitian ini adalah uji normalitas dengan metode Non parametric One-Sample Kolmogorov-Smirnov Test. Pada uji normalitas data diperoleh Standardized Residual sig. $0,325>0.05$, artinya variabel-variabel dalam model regresi ini memiliki distribusi data yang normal.

Setelah semua asumsi terpenuhi, analisis regresi dengan SPSS, dilakukan untuk pengujian hipotesis. Dimana hasil uji hipotesis dapat dilihat pada Tabel 1 berikut :

\section{Tabel 1. Koefisien Regresi}

\begin{tabular}{|c|c|c|c|c|c|c|}
\hline \multicolumn{7}{|c|}{ Coefficients $^{\mathrm{a}}$} \\
\hline & \multirow{3}{*}{ Model } & \multirow{2}{*}{$\begin{array}{l}\text { Unstandardized } \\
\text { Coefficients }\end{array}$} & \multirow{2}{*}{\multicolumn{2}{|c|}{$\begin{array}{l}\text { Standardized } \\
\text { Coefficients }\end{array}$}} & \multirow[t]{3}{*}{$\mathbf{t}$} & \multirow{3}{*}{ Sig. } \\
\hline & & & & & & \\
\hline & & B & Std. Error & Beta & & \\
\hline \multirow[t]{2}{*}{1} & (Constant) & 11.780 & 2.429 & & 4.850 & .000 \\
\hline & POS & .311 & .039 & .637 & 7.932 & .000 \\
\hline
\end{tabular}

a. Dependent Variable: WLB

Sumber : hasil pengolahan data primer (Tahun 2016) 
Tabel 1 menunjukkan bahwa nilai $\mathrm{t}$ hitung lebih besar dari nilai $\mathrm{t}$ tabel pada nilai sig. $0,000<0,05$. Hal ini berarti $\mathrm{H} 0$ ditolak dan H1, diterima. Jadi dapat disimpulkan bahwa penelitian ini dapat membuktikan bahwa POS berpengaruh positif dan signifikan terhadap keseimbangan hidup-kerja (work life-balance) dengan koefisien regresi sebesar $\beta=0,637$. Semakin baik dukungan organisasi yang dirasakan maka semakin baik kualitas keseimbangan hidup-kerja karyawan.

Adapun besaran pengaruh POS terhadap keseimbangan hidup-kerja dapat dilihat pada Tabel 2 berikut :

\section{Tabel 2. Besaran Pengaruh POS terhadap Keseimbangan Hidup-Kerja}

\begin{tabular}{|c|c|c|c|c|}
\hline \multicolumn{5}{|c|}{ Model Summary ${ }^{b}$} \\
\hline Model & $\mathrm{R}$ & R Square & Adjusted R Square & $\begin{array}{c}\text { Std. Error of the } \\
\text { Estimate }\end{array}$ \\
\hline 1 & $.637^{\mathrm{a}}$ & .406 & .400 & 2.92012 \\
\hline
\end{tabular}

Pada tabel 2 di atas diketahui nilai $R$ Square sebesar 0,406 yang artinya besaran pengaruh POS terhadap keseimbangan hidup-kerja adalah sebesar 40,6\% sedangkan $59,4 \%$ ditentukan oleh faktor lain yang tidak diteliti dalam penelitian ini.

POS berpengaruh positif dan signifikan terhadap keseimbangan hidup-kerja (work- life balance). Semakin baik dukungan organisasi yang dirasakan maka semakin baik kualitas keseimbangan hidup-kerja bagi karyawan. Hal ini sejalan dengan penelitian Thakur dan Kumar, (2015) bahwa banyak variabel yang bisa mempengaruhi terciptanya keseimbangan hidup-kerja individu, yang berasal dari faktor pekerjaan, keluarga, dan lingkungan sosial, diantaranya dukungan organisasional yang dirasakan (Perceived Organizational Support / POS).

\section{KESIMPULAN}

Dari penelitian ini dapat diambil kesimpulan bahwa POS berpengaruh positif dan signifikan terhadap keseimbangan hidup-kerja (work- life balance). Dengan demikian jika dukungan organisasi yang dirasakan karyawan baik, maka kualitas keseimbangan hidup-kerja karyawan juga semakin baik. 


\section{DAFTAR PUSTAKA}

Bhagwagar, H. 2009. Need for workplace counseling in India. Http:// prod.bolohealth.com/healthzones/21-total-health/article/165-needfor- workplacecounseling-in-india.

Bharat, B. 2008. Longer working hours for computer software engineers, India. Http://www.saching.com/Article/Longer-working-hours-for- Computer-SoftwareEngineers-India/1088.

Broers, CM. 2005, Career and Family: The Role of Social Support, Griffith University, PhD Thesis.

Burke, R. J. 2002. Organizational values, job experiences and satisfaction among managerial and professional women and men: Advantage men? Women in Management Review. Vol. 17. No.5: 5-6.

Cooper, D. R., \& Schindler, P. S. 2011. Business Research Method 11ed. New York: McGraw-Hill.

Eisenberger, R., Huntington, R., Hutchison, S., \& Sowa, D. 1986. Perceived organizational support. Journal of Applied Psychology, Vol. 71: 500-507.

Guest, E David. (2002). Perspectives on the Study of Work-life Balance, Social Science Information, vol. 41, no. 255, pp. 255-79.

Hair, J. F., Black, W. C., Babin, B. J., \& Anderson, R. E. 2010. Multivariate Data Analysis, $7^{\text {th }}$ Edition. Singapore: Simon \& Schuster Asia Pte, Ltd.

Hill, E. J., Yang, C., Hawkins, A. J., \& Ferris, M. 2004. A cross-cultural test of the workfamily interface in one corporation in 48 countries. Journal of Marriage and the Family, Vol. 66: 1300-1316.

Hyman, J., and J. Summers. 2004. Lacking balance. Personal Review Vol. 33. No.4: 418-429.

Ishaya, N., and R. Ayman. 2008. Predicting work-family conflict via perceive involvement and overload. Boston, ma: American Psychological Association.

Jenkins, M. P. 2000. Work and family in the 1990s. Journal of Marriage and Family Vol. 62. No.4: 981-989.

Kerlinger, F. N., \& Lee, H. B. 2000. Foundations of Behavioral Research $2^{\text {nd }}$. Harcourt College Publisher.

Marcinkus, W. C., K. S. Whelan-Beny, and J. R. Gordon. 2007. The relationship of social support to the work family balance and work outcomes of midlife women. Women in Management Review. Vol. 22. No.2: 86-111. 
Mathieu, I., \& Zajac, D. (1990). A review and meta-analysis of the antecedents, correlates, and consequences of organizational commitment. Psychological Bulletin, Vol. 108, pp. 171-194.

Morgan, H. 2003. The challenges of a global marketplace. In Human resources in the 21 st century, ed. M. Goldsmith, R. Gandossy, and M. Effron. New York: Wiley.

Noor, Khairunneezam Mohd. 2011. Work-Life Balance and Intention to Leave among Academics in Malaysian Public Higher Education Institutionsv. International Journal of Business and Social Science. Vol. 2 No. 11 [Special Issue - June 2011] 240.

Rhoades, Linda. \& Eisenberger, Robert. (2002). Perceived organizational support: A Review of the Literature. Journal of Applied Psychology, Vol 87, No. 4, 698-714.

Robbins, Stephen P. Dan Judge, TImothy A. (2009). Organizational Behviour. $13^{\text {th }}$ Edition. Pearson Education, Inc., Upper Saddle River, New Jersey.

Shankar, Tara \& Bhatnagar. 2010. Work Life Balance, Employee Engagement, Emotional Consonance/Dissonance \& Turnover Intention. Indian Journal of Industrial Relations Vol. 46, No.1. 74-87.

Scholaris, Dora and Mark, Abigail. 2004. Work-life balance and the software workers. Human Resources Management Journal. Vol.14, No.2. pp. 54-74.

Singh, B. 2004. Working women in India. New Delhi: Anmol..

Summer, H. C., and P. A. Knight. 2001. How do people with different attachment styles balance work and family? A personality perspective on work-family linkage. Journal of Applied Psychology. Vol. 86. No.4: 653-663.

Thakur, Aditi \& Kumar, Narsingh. 2015. The Effect of Perceived Organizational Support, Role Related Aspects and Work Involvement on Work-Life Balance: Self Efficacy as a Moderator. International Journal of Scientific and Research Publications, Volume 5, Issue 1, January 20151 ISSN 2250-3153 www.ijsrp.org. 